\title{
Avaliação do conhecimento dos acadêmicos de Odontologia sobre câncer bucal, um
}

\section{estudo transversal}

\author{
Assessment of the knowledge of Dentistry students about oral cancer, a cross-cutting study \\ Evaluación del conocimiento de estudiantes de Odontología sobre cáncer oral, un estudio transversal
}

Recebido: 05/08/2021 | Revisado: 22/08/2021 | Aceito: 03/09/2021 | Publicado: 05/09/2021

\author{
Camila Martins Morales \\ ORCID: https://orcid.org/0000-0001-8578-6863 \\ Centro Universitário Unifacvest, Brasil \\ E-mail: caunifacvest@gmail.com \\ Carla Cioato Piardi \\ ORCID: https://orcid.org/0000-0001-6040-8153 \\ Centro Universitário Unifacvest, Brasil \\ E-mail: caarla.piardi@ hotmail.com \\ Rúbia de Siqueira \\ ORCID: https://orcid.org/0000-0001-6094-3252 \\ Centro Universitário Unifacvest, Brasil \\ E-mail: rubiadesiqueira@hotmail.com \\ Luiz Guilherme Borges \\ ORCID: https://orcid.org/0000-0002-4714-4939 \\ Centro Universitário Unifacvest, Brasil \\ E-mail:borges_luiz98@outlook.com
}

\begin{abstract}
Resumo
Introdução: O câncer é o nome dado a mais de 100 tipos de doenças que acometem os tecidos e órgãos, devido ao crescimento desordenado das células. Existem cerca de 626 mil novos casos de câncer para o ano 2020 no Brasil, desconsiderando o câncer de pele não melanoma. Objetivo: $O$ objetivo do trabalho foi avaliar o conhecimento dos acadêmicos do curso de odontologia regularmente matriculados no Centro Universitário Unifacvest, situado na cidade de Lages/SC, no ano de 2020, sobre o câncer bucal. Metodologia: Foi aplicado um questionário a 199 acadêmicos regularmente matriculados no curso de odontologia, do Centro Universitário Unifacvest, nas fases que realizam atendimento clínico do quinto período ao décimo, nos meses de fevereiro e setembro de 2020. Os dados foram coletados, analisados e contabilizados em planilhas. Após foi realizada a estatística descritiva através de frequências absolutas e percentuais das variáveis relativas à caracterização dos acadêmicos e perguntas respondidas. Resultados: Participaram do estudo 199 acadêmicos com uma amostra predominante do sexo feminino $(71,4 \%)$, esta foi categorizada por clínica não integrada com um total de 62 alunos e clínica integrada com um total de 135 alunos. Conclusão: Portanto, a partir dos resultados apresentados, concluímos o conhecimento dos acadêmicos como positivo, somado a isso a importância do cirurgião-dentista frente ao diagnóstico do câncer bucal. Apontamos a importância da prevenção, bem como a disciplina de patologia bucal, em conjunto com a clínica integrada.
\end{abstract}

Palavras-chave: Ensino; Câncer bucal; Acadêmicos de Odontologia; Conhecimento; Questionário.

\begin{abstract}
Introduction: Cancer is the name given to more than 100 types of diseases that affect tissues and organs, due to the disordered growth of cells. There are about 626,000 new cases of cancer for the year 2020 in Brazil, excluding non-melanoma skin cancer. Objective: The objective of this study was to evaluate the knowledge of dental students regularly enrolled at Centro Universitário Unifacvest, located in the city of Lages/SC, in 2020, about oral cancer. Methodology: A questionnaire was applied to 199 students regularly enrolled in the dentistry course at Centro Universitário Unifacvest, in the phases that perform clinical care from the fifth to the tenth period, in February and September 2020. Data were collected, analyzed and accounted for in spreadsheets. Afterwards, descriptive statistics were performed using absolute frequencies and percentages of variables related to the characterization of students and answered questions. Results: A total of 199 students participated in the study, with a predominantly female sample of $71.4 \%$, which was categorized by non-integrated clinic with a total of 62 students and integrated clinic with a total of 135 students. Conclusion: Therefore, based on the results presented, we conclude that the students' knowledge is positive, in addition to the importance of the dentist in the diagnosis of oral cancer. We point out the importance of prevention, as well as the discipline of oral pathology, together with the integrated clinic.
\end{abstract}

Keywords: Teaching; Oral cancer; Dentistry academics; Knowledge; Quiz. 


\begin{abstract}
Resumen
Introducción: Cáncer es el nombre que se le da a más de 100 tipos de enfermedades que afectan tejidos y órganos, debido al crecimiento desordenado de las células. Hay alrededor de 626.000 nuevos casos de cáncer para el año 2020 en Brasil, sin incluir el cáncer de piel no melanoma. Objetivo: El objetivo de este estudio fue evaluar el conocimiento de los estudiantes de odontología matriculados regularmente en el Centro Universitario Unifacvest, ubicado en la ciudad de Lages / SC, en 2020, sobre el cáncer oral. Metodología: Se aplicó un cuestionario a 199 estudiantes matriculados regularmente en el curso de Odontología del Centro Universitário Unifacvest, en las fases que realizan la atención clínica del quinto al décimo período, en febrero y septiembre de 2020. Los datos fueron recolectados, analizados y contabilizados en hojas de cálculo. Posteriormente, se realizó estadística descriptiva utilizando frecuencias absolutas y porcentajes de variables relacionadas con la caracterización de los estudiantes y preguntas respondidas. Resultados: Participaron del estudio 199 estudiantes, con una muestra predominantemente femenina del $71,4 \%$, la cual fue categorizada por clínica no integrada con un total de 62 estudiantes y clínica integrada con un total de 135 estudiantes. Conclusión: Por tanto, con base en los resultados presentados, se concluye que el conocimiento de los estudiantes es positivo, además de la importancia del odontólogo en el diagnóstico del cáncer bucal. Señalamos la importancia de la prevención, así como la disciplina de la patología bucal, junto con la clínica integrada.
\end{abstract}

Palabras clave: Enseñando; Cáncer oral; Académicos de Odontología; Conocimiento; Prueba.

\title{
1. Introdução
}

Conforme consta no INCA (Instituto Nacional de Câncer José Alencar Gomes da Silva), existem cerca de 626 mil novos casos de câncer no Brasil para o ano de 2020, desconsiderando o câncer de pele não melanoma. Há uma estimativa de 11.108 novos casos em homens e 4.010 em mulheres a cada 100.000 habitantes. Os indivíduos do sexo masculino acima de 40 anos são os mais acometidos pela doença, e jovens que fazem o uso de tabaco e álcool também podem desenvolver a doença. Todas as formas de tabaco (cigarros, cachimbos, charutos e sache de Betel), são fatores de risco para o desenvolvimento do câncer bucal.

O uso de álcool é o segundo maior fator de risco, assim como outros fatores, entre eles o papilomavírus humano (HPV), dieta e exposição solar (Khalili, 2008). O câncer é o nome dado a mais de 100 tipos de doenças que acometem os tecidos e órgãos, onde devido ao crescimento desordenado das células onde ocorre uma divisão agressiva e incontrolável, a qual desenvolvem tumores, sendo que existem diferentes tipos que são classificados de acordo com suas variedades de células do corpo. É uma doença comum de etiologia multifatorial que acomete milhares de brasileiros, destaca-se o câncer bucal o qual atinge a região de cabeça e pescoço. Por exemplo, os que iniciam pelos tecidos epiteliais, como pele ou mucosas, são denominados carcinomas, e os que o ponto de partida são os tecidos conjuntivos como, osso, músculo ou cartilagem, são chamados sarcomas conforme descrito por Farah et al. (2017).

O carcinoma espinocelular (CEC) é responsável por cerca de $90 \%$ das neoplasias malignas orais e está entre os tipos de câncer mais frequentes nos seres humanos. Os outros $10 \%$ estão divididos entre o pleomórfico indiferenciado, que é uma neoplasia mesenquimal classificada como tumores de tecido mole, sua etiologia é desconhecida, entretanto há tendência de ser idiopática. São raros e agressivos com altos índices de recidiva (Moreira et al. 2017). Neville et al. (2009) citam os carcinomas de glândulas salivares, que podem se desenvolver na mucosa oral perto da garganta, os linfomas que podem se desenvolver na base da língua e carcinoma de vermelhão do lábio.

Para um bom diagnóstico, o cirurgião-dentista ou médico deverão ter amplo conhecimento sobre o câncer oral, além de saber fazer um exame físico completo sempre analisando se há feridas que não cicatrizam por mais de 15 dias, manchas/placas vermelhas ou esbranquiçadas na língua, assoalho bucal, gengivas, palato, mucosa jugal, linfonodos infartados no pescoço. Geralmente quando há presença de linfadenopatias regional e rouquidão persistente, a possibilidade de encontrar uma lesão de câncer na cavidade bucal no mesmo lado é grande (Prado, Andrade, 2016; Neville et al. 2009).

O câncer quando é diagnosticado no começo tem grande chance de cura, seu tratamento vai depender da região em que se encontra o tumor e das alterações funcionais. O médico irá decidir a melhor forma de tratamento, podendo ser desde uma cirurgia oncológica, radioterapia isolada ou a associação dos dois tipos. Quando é feita combinação dos tratamentos, se tem bons resultados, 
isto quando realizados no início da lesão. As regiões mais acometidas são lábios, assoalho bucal, gengivas, bochechas, palato, língua (OMS, 2019).

Para que se obtenha um bom diagnóstico, os cursos de graduação devem preparar os estudantes e habilitá-los para identificar quaisquer agravos do sistema estomatognático. Assim, a avaliação do conhecimento acadêmico em diferentes estágios da formação, é um meio de mensurar a capacitação desses futuros profissionais, diante das diferentes alterações orais, especialmente do câncer bucal (Silva et al. 2016). A literatura atual demonstra um nível baixo de conhecimento dos acadêmicos de odontologia sobre câncer bucal e segundo o estudo de Lopes et al. (2015), por exemplo, 55,5\% do total dos alunos entrevistados relataram não realizar o exame de câncer de boca por falta de conhecimento.

Nessa perspectiva, o propósito desta pesquisa foi avaliar o conhecimento dos acadêmicos do curso de odontologia, regularmente matriculados no Centro Universitário Unifacvest, situado na cidade de Lages/SC, no ano 2020, a respeito do câncer bucal.

\section{Metodologia}

O projeto que deu origem a pesquisa, foi submetido ao Comitê de Ética em Pesquisa (CEP) da Instituição para avaliação, número do Certificado de Apresentação de Apreciação Ética (CAAE) 26370819.0.0000.5616, número do parecer 3.763.282.

Logo após foi realizada uma busca bibliográfica nas bases de dados PubMed, SciELO e Google Acadêmico entre os anos 2008 a 2020. As palavras-chave que foram utilizadas na busca foram câncer bucal, acadêmicos, odontologia, conhecimentoe questionário, onde foram utilizados os marcadores boolianos OR e AND.

Esta pesquisa caracterizou-se como observacional transversal, com aplicação de um questionário contendo perguntas fechadas, elaborado pelo pesquisador e baseadas em alguns questionários validados na literatura (Angheben et al. 2013; Prado, Andrade, 2016). O questionário contém também dados sociodemográficos dos participantes (idade, sexo, semestre), variáveis sobre diagnóstico e prevenção do câncer bucal.

\subsection{Critérios de inclusão}

Acadêmicos regularmente matriculados no curso de odontologia da Instituição Centro Universitário Unifacvest, localizada na cidade de Lages/SC, no ano de 2020/01, nas fases que realizam atendimento clínico, do quinto período ao décimo, totalizando uma média de 250 alunos.

\subsection{Critérios de exclusão}

Foram excluídos do estudo os alunos matriculados que ainda não tiveram a disciplina de clínica e também acadêmicos que não concluíram a disciplina de patologia oral.

A coleta de dados ocorreu nos meses de fevereiro e setembro de 2020. Em um primeiro momento foi entregue o Termo de Consentimento Livre e Esclarecido (TCLE) que após a leitura do mesmo, os que concordaram em participar da pesquisa o assinaram. Foi realizada a coleta de dados dos acadêmicos, através de um questionário para preenchimento, contendo 15 questões. Estes foram orientados para o preenchimento correto, explicados da finalidade da pesquisa, que deveria ser respondido no ato da entrega e não sendo permitido pesquisar. No segundo momento da coleta foi utilizado o questionário eletrônico elaborado no Google formulários e assim concluir a coleta de dados.

\subsection{Análise de dados}

Os dados foram analisados através de um levantamento das informações contidas nos questionários, a qual após coletados e contabilizados em planilhas no programa Microsoft Excel 2010®. 
Após foi realizada a estatística descritiva através de frequências absolutas e percentuais das variáveis relativas à caracterização dos acadêmicos e perguntas respondias. A amostra foi categorizada por alunos que estão cursando a clínica integrada, e alunos que não cursam a clínica integrada. A comparação entre grupos foi feita por meio do teste t para amostras independentes e a comparação entre grupos para a variável sexo foi feita pelo teste de Qui-quadrado.

\section{Referencial Teórico}

\subsection{Câncer}

O câncer é de etiologia multifatorial, sob ação de agentes intrínsecos e extrínsecos, divisão descontrolada de algum tipo de célula, predisposição genética e histórico familiar. Sabe-se que nosso organismo está preparado para que aconteça uma divisão celular sempre que acontece um ferimento em alguma parte de nosso corpo, através de ordens químicas as células se dividem afim de fechar o ferimento. Quando terminam o fechamento da lesão, recebem ordem para parar e param. Já as células cancerosas não param, quando há essa ordem elas continuam se dividindo intensamente, formando novos vasos sanguíneos, que recebem oxigênio e nutrientes, que acabam enganando o sistema imunológico. Com isso algumas células conseguem penetrar na corrente sanguínea e acabam chegando até vários órgãos distantes, e assim formando novos tumores, o qual é denominado metástase (Moro et al. 2020).

A metástase ocorre através de vasos linfáticos e com isso pode atingir qualquer parte do corpo, metástase a distância é denominada quando atinge regiões abaixo da clavícula, por exemplo os pulmões, fígado e ossos são os sítios mais comuns acometidos (Neville et al. 2009). O câncer é chamado carcinoma, quando ocorre em tecidos epiteliais, e quando ocorre em tecido conjuntivo, é denominado sarcoma (Silva et al. 2018).

\subsubsection{Oncogenes e genes supressores de tumores}

Existem quatro classes de genes que são alvos de neoplasias malignas, os genes promotores e inibidores do crescimento e o os genes reguladores do apoptose e reparo do DNA. Os oncogêneses são classificados como genes que promovem o crescimento celular autônomo. Já os proto-oncogenes são os reguladores fisiológicos da proliferação e diferenciação, podendo se transformar em oncogêneses através de mutações na estrutura genética e mudar a regulação da expressão genética. Os genes supressores de tumor (GST) codificam as proteínas que inibem a divisão celular, assim o GST que mais é alterado em células malignas é o P53, além dos tumores epiteliais, são encontradas mutações em outros tipos de tumores (Neville et al. 2009).

\subsubsection{Câncer bucal}

O câncer oral é o décimo primeiro mais comum no mundo e mais de $94 \%$ de suas malignidades são os carcinomas de células escamosas (CCE). O seu risco aumenta de acordo com a idade e é mais prevalente em homens. O CCE é multifatorial, nenhum fator carcinógeno tem sido definido, entretanto os fatores extrínsecos e intrínsecos podem estar associados. Suas características radiográficas são radiolucidez irregular em forma de "roído de traça" com margens irregulares e envolvimento ósseo (Neville et al. 2009).

Segundo o INCA (2019), câncer de boca afeta várias regiões da cavidade oral como lábios, gengivas, bochechas, palato e língua, contudo a prevalência é na região do lábio inferior.

\subsection{Lesões potencialmente malignas}

\subsubsection{Leucoplasia}

A leucoplasia tem como característica uma mancha ou placa branca que pode ser confundida com outras lesões, onde cerca de 70\% são encontradas no vermelhão do lábio, mucosa jugal e gengiva. Já lesões no vermelhão do lábio, língua e assoalho de boca em $90 \%$ exibem displasia ou carcinoma. Afeta mais pessoas acima dos 40 anos e tem sido observado que essa lesão ocorre em média 
5 anos antes do que o carcinoma de células escamosas (CCE), por isso é necessário um bom diagnóstico físico e o exame histopatológico, sendo que as lesões podem se diferenciar conforme o tempo. Por exemplo, leucoplasia inicial, fina ou delgada, leucoplasia espessa ou homogênea, leucoplasia nodular ou granular, verrucosa proliferativa, e se tornar displasias como eritroleucoplasia (Neville et al. 2009).

De acordo com estudo realizado por (MAIA et al. 2016), a leucoplasia é a lesão cancerizável mais frequente da cavidade bucal, no qual correspondeu a $70,7 \%$ dos casos.

\subsubsection{Eritroplasia}

A eritroplasia tem característica de mancha vermelha, os sítios mais comuns são assoalho bucal, língua e palato mole. A prevalência por idade é acima dos 40 anos, a área afetada mostra uma mácula ou placa eritematosa bem delimitada, sendo que geralmente é assintomática e pode estar associada a uma leucoplasia (Neville et al. 2009). Conforme estudo de (Santos, Sá, Lamarck, 2019) a eritroplasia é menos comum na cavidade oral, mas quando encontrada em assoalho bucal tem grande chance de se tornar um carcinoma.

\subsubsection{Quelite actínica}

A quelite actínica é uma alteração pré-maligna comum no vermelhão do lábio, a qual resulta de uma exposição solar excessiva, acomete pessoas acima dos 45 anos e se desenvolve tão lentamente que os pacientes não estão cientes dessa condição (Neville et al. 2009).

A quelite actínica é uma condição patológica que afeta o lábio inferior, que se apresenta com um aspecto atrófico, pálido e frequentemente com fissuração, afetando mais idosos (Santos, Sá, Lamarck, 2019).

\subsubsection{Líquen plano}

O líquen plano é considerado uma doença crônica autoimune mediada por linfócitos T que afeta o epitélio escamoso estratificado, suas características são reticular, erosiva, atrófica, tipo placa, pápula e bolhosa, onde destaca-se como lesão clássica estrias brancas bilaterais (Canto et al. 2002).

De acordo com diversos estudos, a OMS (2019) classifica que com o passar dos anos o líquen plano pode se tornar uma lesão potencialmente maligna, apresentada na fase erosiva $6 \%$ dos casos.

\subsection{Condições potencialmente cancerizáveis}

\subsubsection{Xeroderma pigmentoso}

Xeroderma pigmentoso (XP) é uma doença rara que se desenvolve através de mutações em genes específicos no reparo do DNA, se manifesta clinicamente após exposição solar, devido a pele ter sofrido defeitos na sua formação e apresentar sensibilidade. Pode causar sérios danos e ocasionar o aparecimento de neoplasias malignas na pele, mucosas dos olhos e cavidade bucal. Em alguns pacientes, pode causar também degeneração neurológica progressiva, apresenta padrão de herança autossômico recessivo, por isso qualquer casal com uma criança afetada, o risco de que uma segunda criança venha a apresentar XP é de 25\% (Niedernhofer et al. 2011).

Os primeiros sinais clínicos são eritemas, descamação, hiperpigmentação difusa e lesões cutâneas que se assemelham a sardas (Digiovanna, Kraemer, 2012). Quando há uma evolução das lesões cutâneas pode levar ao aparecimento de ceratoses actínicas (lesões pré-malignas), seguidas de câncer de pele, mais comumente carcinomas (basocelular e espinocelular) e melanomas (Tamura et al. 2014). 


\subsubsection{Anemia fanconi}

A anemia de fanconi (AF) é uma síndrome de instabilidade genômica rara, que se caracteriza clinicamente pela presença de malformações específicas ao nascimento por insuficiência progressiva da medula óssea que tem predisposição ao câncer, principalmente o carcinoma espinocelular (D'agulham et al. 2014).

As lesões orais que são visíveis em pacientes com AF, são muitas e crônicas. Com isso a biópsia oral com análise do gene de DNA torna-se alternativa não invasiva que pode ser usada para detectar CEC oral (Velleuer et al. 2020).

\subsection{Características, fatores de risco, diagnóstico e tratamento}

\subsubsection{Características clínicas e radiográficas}

O carcinoma de células escamosas oral apresenta algumas características clínicas importantes para um diagnóstico inicial como lesões exofítica (que apresenta um aumento de volume, vegetante, papilar e verruciforme), endofítica (invasiva, escavada e ulcerada), leucoplásica (mancha branca), eritroplásica (mancha vermelha), e leucoeritroplásica (combinação de áreas vermelhas e brancas), já características radiográficas apresentam uma destruição do osso subjacente, podendo apresentar dor. Na imagem radiográfica aparecerá uma radiolucidez com aspecto de "roído de traça" com margens mal definidas ou irregulares (Neville et al. 2009).

Destacam-se que alguns aspectos clínicos como ulcerações e manchas leucoeritroplásicas na mucosa oral, que não cicatrizam num período superior a 15 dias e que são assintomáticas em sua maioria, são os achados mais comumente encontrados (Moro et al. 2018).

\subsubsection{Fatores de risco}

De acordo com a OMS, $80 \%$ da prevenção efetiva do câncer de boca está relacionado com fatores ambientais. Por isso o conhecimento dos fatores de risco constitui a base para uma boa prevenção. Destacam-se como alguns fatores de risco para o câncer oral a conduta e dieta do indivíduo, como a baixa ingestão de alimentos, entre eles proteínas, frutas e verduras. Além desses fatores ressaltam-se os mais importantes como o tabaco, álcool e a exposição solar excessiva sem proteção ao longo dos anos que se constituem como um fator de risco para o câncer de boca, especialmente o de lábio (Andrade, Santos, Oliveira, 2015; Santos, Sá, Lamarck, 2019).

\subsubsection{Câncer e dieta}

O baixo consumo de frutas, vegetais e uma dieta rica em gorduras, tem maior predisposição para o aparecimento do câncer bucal devido ao fato que pode reduzir a imunidade, desencadear processos de ceratinização excessiva e aumentar os radicais livres contribuindo para a ativação de oncogenes (Pinheiro, Cardoso, Prado, 2010).

\subsubsection{Agentes fenólicos}

O uso de muitos alimentos industrializados no qual tem grande quantidade de agentes fenólicos, apresentam oxidação lipídica e a proliferação de fungos (Soares, 2002). Também, os trabalhadores de indústrias de produtos derivados da madeira no qual ficam expostos a agentes químicos, como os ácidos fenoxiacéticos, tem um risco aumentado para o desenvolvimento de câncer (Neville et al. 2009).

\subsubsection{Deficiência de ferro}

A deficiência de ferro pode ser um dos possíveis fatores etiológicos do câncer bucal. O baixo consumo de proteínas, faz com que o organismo desenvolva anemia ferropriva, devido à dificuldade de absorção, pela dificuldade de poder adquirir alimentos 
ricos em ferro ou também à dificuldade de poder mastigar diminui a absorção do ferro. Síndrome de Plummer-Vinson é uma doença que se desenvolve devido à deficiência de ferro em fase grave ou crônica, que atinge a região superior do trato gástrico digestivo. $\mathrm{O}$ ferro é importante para o funcionamento das células epiteliais e se há deficiência na renovação dessas células a mucosa se torna atrófica ou imatura (Neville et al. 2009).

\subsubsection{Imunossupressão}

Neville e seus colaboradores (2009), relatam que pessoas com acquired immunodeficiency syndrome (AIDS), a qual estão sendo submetidos a tratamentos, apresentam risco elevado para o desenvolvimento de CCE, principalmente quando associados ao uso de álcool e tabaco.

\subsubsection{Deficiência de vitamina A}

Alguns pesquisadores apontam que a vitamina A pode ter um fator importante na prevenção do pré-câncer e do câncer oral. Acreditam que os níveis sanguíneos de retinol e a quantidade de betacaroteno ingeridos na dieta ajudam a não desenvolver carcinomas. A terapia com ácidos retinóicos e betacaroteno tem regredido algumas lesões leucoplasicas em fases iniciais (Neville et al. 2009).

\subsubsection{Câncer e tabaco}

Os constituintes do tabaco provocam oxidações nos tecidos, no qual produzem radicais livres que são capazes de agredir o DNA, o que causa alterações que levam ou surgimento do carcinoma escamoso, sendo que o risco de desenvolver esse tipo de câncer é 6 a 9 vezes maior em tabagistas. Esse risco será proporcional ao tempo de exposição e à dose, têm mais riscos os fumantes crônicos quando comparados a não-fumantes (Bittencourt et al. 2017).

O tabagismo isoladamente está classificado como principal causa de câncer no mundo e constitui o fator primordial em 90\% dos casos (Sakaguti, 2018; Lamin, Silva, Souza, 2011). De acordo com a OMS, a nicotina que está presente na fumaça do cigarro é considerada droga psicoativa que causa dependência. O hábito de fumar está associado a leucoplasias, mais de $80 \%$ dos pacientes examinados apresentam essa lesão, e a maioria que para de fumar tem a regressão da mesma (Neville et al. 2009).

\subsection{Tabaco sem fumaça}

O tabaco sem fumaça é dividido em três tipos, o de mascar, o rapé úmido e o rapé seco, ambos exercem uma série de efeitos adversos sobre os dentes e estruturas adjacentes. O hábito de fumar cigarro sem fumaça produz um efeito diferente na mucosa oral, caracterizado por uma placa branca a qual é denominada ceratose da bolsa de tabaco e essa lesão aparece entre 1 a 5 anos. As pessoas que fazem uso dessa forma de tabaco apresentam grande chance de desenvolver lesões no mesmo lado que o mastigam (Neville et al. 2009).

Conforme apontou (Iarc, 2004), o tabaco sem fumaça tem grande potencial de risco para o câncer oral, baseando-se em avaliações realizadas em casos-controles e de coorte, além de experimentos realizados in vitro e in vivo.

\subsection{Fibrose submucosa}

Lesão crônica, progressiva, de condição pré-cancerosa com alto risco na mucosa oral, apresenta rigidez variada na mucosa, provocada por hiperplasia fibroelástica e modificação do tecido conjuntivo. A queixa principal desta lesão é o trismo, acompanhada de dor na mucosa (Neville et al. 2009). Está relacionada ao uso crônico do sachê de Betel, o qual consiste a presença de cal hidratada e noz da palmeira de areca que pode ser associado junto ao tabaco ou adoçantes e condimentos embalados em folha de Betel, a qual 
se tem o costume de mascar essa folha por causar efeitos de bem-estar em seus usuários e está sendo frequentemente usada população jovem do norte da Índia (Goyal, Bhagawati, 2016).

\subsubsection{Câncer e álcool}

O uso de álcool é um dos fatores responsáveis pelo câncer de boca pelo fato de que a substância alcoólica atinge diretamente a mucosa oral. Entretanto a quantidade ingerida e a frequência da mesma que será o fator desencadeador do tumor (Carrard et al. 2008). Algumas pesquisas feitas in vitro demonstram que a partir da aplicação tópica, o álcool já consegue mudar a permeabilidade da mucosa bucal, que tem a capacidade de estimular a proliferação epitelial e também diminui a reparação do DNA (Yokoi et al. 2015).

\subsubsection{8 Álcool e tabaco}

O alto consumo de álcool quando associado ao uso de tabaco, chega-se ao prognóstico de câncer bucal, devido ao fato de que quanto maior o seu consumo, maior será o risco de desenvolvimento. A associação dos dois facilita a infiltração dos carcinógenos presentes no tabaco (Goyal, Bhagawati, 2016; Santos et al. 2010).

O tabaco e álcool tem grandes fatores carcinogênicos, com isso o uso associado tem resultados tão agravantes para o desenvolvimento do câncer devido a modificação dos genes e alteração da molécula de DNA favorecendo a indução do câncer (Roco et al. 2018).

\subsubsection{Câncer e exposição solar}

A radiação emitida pelo sol está associada com o aparecimento do câncer de lábio inferior e as radiações ionizantes podem além de causar anormalidades cromossômicas, reduzir a reatividade imunológica (Pinheiro, Cardoso, Prado, 2010). Pessoas que moram em áreas mais quentes, expostos a muita luz solar, fazem parte do grupo de risco a desenvolver tumor (Mauricio, Matos, Guimarães, 2009).

\subsubsection{Câncer e HPV}

O papilomavírus humano (HPV) é da família do papilomaviridae, possui o genoma de DNA com fita dupla circular, suas variantes têm modificação de até $10 \%$ do genoma viral original, fazem parte de um grupo de mais de 100 tipos de vírus e a infecção por alguns tipos de HPV podem desenvolver câncer, sendo que a maioria das infecções de boca por HPV não apresentam sintomas (Assis et al. 2020).

O papel do HPV é bem reconhecido em algumas lesões bucais benignas como por exemplo no condiloma acuminado, verruga vulgar, hiperplasia epitelial focal e no papiloma (Melo et al. 2010). O HPV é dividido em dois grupos de acordo com o potencial oncogênico, de baixo risco que desenvolvem lesões de baixo grau e de alto risco que estão relacionadas a lesões na zona de transformação cervical e anal, bem como nas criptas da orofaringe são locais onde a expressão do gene viral é mal controlada (Egwa et al. 2015).

Os subtipos mais relacionados com o CEC são o 16,18,31, e 33, por envolver duas proteínas codificadas pelo vírus que são a E6 e E7 que promovem a degradação do produto do gene P53 (Neville et al. 2009).

Apesar de existem indícios da ação carcinogênica do HPV no desenvolvimento de neoplasias bucais, não se pode afirmar por existir resultados inconclusivos e divergentes sobre seu real papel (Furtado et al. 2019). 


\subsubsection{Sífilis e câncer}

A sífilis é uma doença infecciosa causada pela bactéria espiroqueta treponema pallidum, subespécie Pallid. Seu contágio pode ser através de relações sexuais ou congênita, e está classificada em alguns estágios como primários, secundários, latente e terciário, podendo se manifestar em vários órgãos e tecidos (Santos, Sá, Lamarck, 2019).

No estágio inicial e secundário o seu contágio é maior, por isso o cuidado com a transmissão deve ser redobrado. Nessa fase, o diagnóstico tem que ser preciso para que não passe para fase latente, não apresente mais sinais clínicos, volte mesmo após anos a se manifestar na fase terciária, e causar sérios danos ao organismo. Na cavidade oral, essa fase pode manifestar sinais e assemelhar-se a lesões potencialmente malignas ou grandes a ulcerações por várias regiões da cavidade bucal levando até a morte (Souza et al. 2017).

Acredita-se que a sífilis terciária tem grande associação ao desenvolvimento de CEC em região de dorso de língua. A terapia utilizada antigamente para tratar as lesões de sífilis com agentes arsênicos e metais pesados, apresentavam propriedades carcinogênicas intrínsecas e podem ter influenciado no aparecimento de câncer. Entretanto as malignidades associadas são raras devido ao fato de serem diagnosticadas e tratadas em fases iniciais (Neville et al. 2009).

\subsubsection{Infecção por cândida}

A candidíase hiperplásica tem sido citada como uma condição pré-cancerosa oral, devido seu surgimento ser uma placa branca em que não se destaca conhecida como leucoplasia por cândida. Tanto clinicamente ou histologicamente é difícil diferenciar a candidíase hiperplásica de uma leucoplasia preexistente e apesar de alguns tipos de cândida apresentarem potencial para desenvolver câncer oral, não existe evidencia até o momento (Neville et al. 2009).

\subsubsection{Radioterapia}

A associação de radioterapia em pacientes imunodeprimidos ou transplantados tem causado aparecimento de lesões potencialmente malignas, efeito dose-dependente, sendo que essas lesões aparecem principalmente no vermelhão do lábio (Neville et al. 2009).

\subsubsection{Diagnóstico}

É imprescindível a realização de um exame físico completo, avaliando todas as áreas com precisão, sendo necessário também analisar possíveis traumas que podem haver por uso inadequado de próteses, por exemplo. As regiões devem ser sempre palpadas para poder sentir os limites acometidos, se há feridas que não cicatrizam por mais de 15 dias, manchas/placas vermelhas ou esbranquiçadas na língua, gengivas, palato (céu da boca), mucosa jugal (bochecha) nódulos (caroços) no pescoço ou rouquidão persistente. Sempre que diagnosticar uma lesão de câncer é indispensável ver suas características e dimensões para detalhar se é necrosado, ulcerado, infiltrativo e se há indícios de invasão óssea ou da musculatura profunda. O diagnóstico só é confirmado através de um exame citopatológico ou biópsia, a qual será feita uma análise da lesão (OMS, 2018; Prado, Andrade, 2016).

O exame de biópsia é indicado para complementar o exame físico, assim como outros exames complementares, dentre eles a tomografia computadorizada e a ressonância magnética que são indicadas em casos que no exame físico não se consiga ter um diagnóstico preciso (Neville et al. 2009). De acordo com o estudo de Freitas et al. (2016), citopatologia é um método novo de detectar alterações celulares em estágios iniciais e os sítios anatômicos apresentam diferentes graus de maturação epitelial.

\subsubsection{Tratamento}

O tratamento do câncer de boca requer um atendimento multidisciplinar por ser um tratamento complexo que envolve a fala e a deglutição, pois apesar do avanço tecnológico, a mortalidade ainda é grande mesmo que a qualidade de vida melhorou, devido às 
técnicas de cirurgias reconstrutivas. Ainda se tem um grande desafio na deteção precoce da doença pois o conhecimento entre os profissionais e as pessoas ainda é muito baixo (Miloro et al. 2016).

O grau de evolução e a localização do tumor primário tumor-linfonodos-metástase (TNM), vai direcionar o índice de sobre vida do paciente, por isso o diagnóstico precoce das lesões irá direcionar os possíveis tratamentos de acordo com o estágio que se encontra a lesão, I, II, I, ou IV (Neville et al. 2009).

De acordo com a OMS (2019), a grande maioria dos casos de câncer da cavidade oral tem cura e o seu tratamento geralmente envolve cirurgias e radioterapia ou a associação desses dos dois tratamentos, contudo a avaliação médica e o seu conhecimento são imprescindíveis para decidir qual será a melhor forma de tratamento.

Quando se encontra tumores já em estágios avançados, os tratamentos tendem a ser mais radicais, estes incluem cirurgias extensas, radioterapia com doses exaustivas e quimioterapia que são empregadas de formas isoladas ou concomitantes. Nesses casos, a associação de laserterapia pode ser associada durante e depois do tratamento radioterápico com o objetivo tanto de prevenir como também tratar mucosite e xerostomia (Santos, Dib, Souza, 2020).

\subsubsection{Efeitos adversos do tratamento}

Os tratamentos para lesões de cabeça e pescoço causam alguns efeitos adversos, como por exemplo, a mucosite oral. É um dos efeitos ocasionados pela radioterapia e quimioterapia durante o tratamento, pode ocorrer na boca do paciente causando grande desconforto na fala, deglutição e na ingestão de alimentos (Marinho et al. 2013).

A mucosite apresenta-se como um dos principais efeitos colaterais no tratamento de câncer de cabeça e pescoço provocados pela radioterapia no DNA, resultando a perda da capacidade de proliferação das células basais do epitélio (Lopes et al. 2020).

A mucosite oral está relacionada com tratamentos de quimioterapia e radioterapia, apresentam semelhança clinicamente e a diferença entre as duas será o local afetado. Na quimioterapia será na mucosa jugal, ventrolateral da língua, palato mole e soalho oral. Já na radioterapia o local afetado será onde a radiação atinge, sendo que ambos tratamentos desaparecem de 2 a 3 semanas após o término (Neville et al. 2009).

A xerostomia associada a radioterapia está relacionada ao fato de que as glândulas salivares são sensíveis a radiação. Apresentam mudança após uma semana de início do tratamento, mas só é possível perceber os efeitos a partir da sexta semana de tratamento, no qual há uma diminuição do fluxo salivar. Há uma secura na boca, que perde sua lubrificação e pode causar desconfortos no uso de próteses, na alimentação e aparecimento de lesões de cárie (Neville et al. 2009).

Candidíase associada a radioterapia tem sido relatada por várias pesquisas como um risco significativamente aumentado de infecção fúngica bucal, se manifesta em quase $50 \%$ dos pacientes com câncer de cabeça e pescoço, durante e após o tratamento. O diagnóstico baseia-se na apresentação clássica e resposta à terapia antifúngica ou pode exigir amostragem microbiológica de uma lesão em um cotonete simples (Lopes et al. 2020).

A osteorradionecrose é a complicação mais seria de efeitos adversos da radioterapia, apresenta menor frequência cerca de 5\% atualmente. Apesar de ser baixa a ocorrência, ela pode aumentar se ocorrer cirurgia local, em menos de 21 dias do começo do tratamento ou 12 meses após o termino do tratamento radioterápico. A mandíbula é acometida com mais frequência e a dose da radiação é o principal fator de necrose óssea (Neville et al. 2009).

A radioterapia é o tratamento mais eficaz para o câncer de cabeça e pescoço, mas seu uso em grande quantidade traz um grande efeito colateral ao organismo, ao emitir a radiação ionizante nas células que apresentam mutação, atingem também as células saudáveis e com isso trazendo efeitos adversos ao DNA (Lopes et al. 2020). 


\section{Resultados e Discussão}

O presente estudo teve como objetivo descrever o nível de conhecimento de um grupo de acadêmicos de odontologia do Centro Universitário Unifacvest, acerca do câncer bucal, ao avaliar a confiança dos acadêmicos frente ao diagnóstico do câncer de boca, ambos os participantes relatam se sentir pouco confiantes.

Após busca bibliográfica, foi criada uma tabela 1, na qual contém 12 estudos relacionados ao conhecimento do câncer bucal. Um estudo de caso-controle, envolvendo 254 participantes, que avaliou o conhecimento e o perfil sociodemográfico dos participantes. Dois estudos transversais avaliaram o conhecimento dos acadêmicos sobre o câncer bucal. Três estudos descritivos avaliando o conhecimento dos estudantes sobre os fatores de risco para o câncer oral. Três estudos descritivos e estatísticos compararam o nível de conhecimento dos acadêmicos que estão em fases iniciais, dos que já estão em fases finais. Um estudo exploratório e dois estudos de coorte-transversais. Foram convidados a participar do presente estudo 250 acadêmicos do curso de odontologia, divididos entre alunos que estão cursando a clínica integrada e alunos que ainda não estão cursando (Figura 1). Houve uma diferença estatisticamente significante entre os grupos ( $\mathrm{P}<0,05$ pelo teste de Qui-quadrado).

Figura 1. Fluxograma.

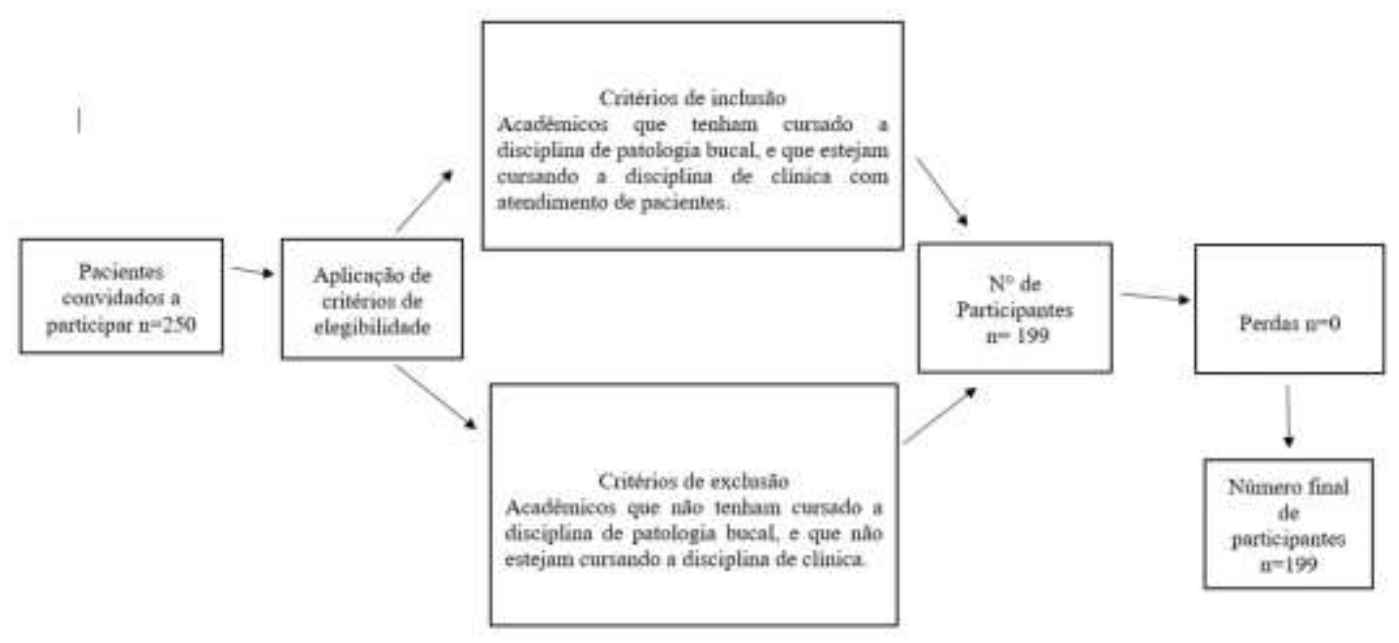

Fonte: Autores.

Aceitaram participar do estudo 199 alunos das fases $5^{\mathrm{a}}, 6^{\mathrm{a}}, 7^{\mathrm{a}}, 8^{\mathrm{a}}, 10^{\mathrm{a}}$ atual e $10^{\mathrm{a}}$ formada (Figura 2), após assinaram o TCLE. Do total de participantes, $71,4 \%$ era do sexo feminino, $27,6 \%$ do sexo masculino e 1,0\% não respondeu. Dos 199 participantes, a média de idade entre foi 23,4 ( $(3,9)$ anos, com uma idade mínima de 19 anos e máxima de 51 anos, assim como nos achados de Prado e Andrade (2016), onde a idade dos estudantes variou, em média, de 23,1 anos.

Quando questionados sobre sentir confiança ao diagnosticar o câncer bucal, 69,8\% relataram sentirem-se pouco confiantes. Em relação à frequência do exame dos tecidos moles, 56,8\% o realizam, dados que diferem do estudo de Lopes et al. (2015), onde $55 \%$ dos acadêmicos não realizam o exame por falta de conhecimento. 
Figura 2. Alunos participantes por fase.

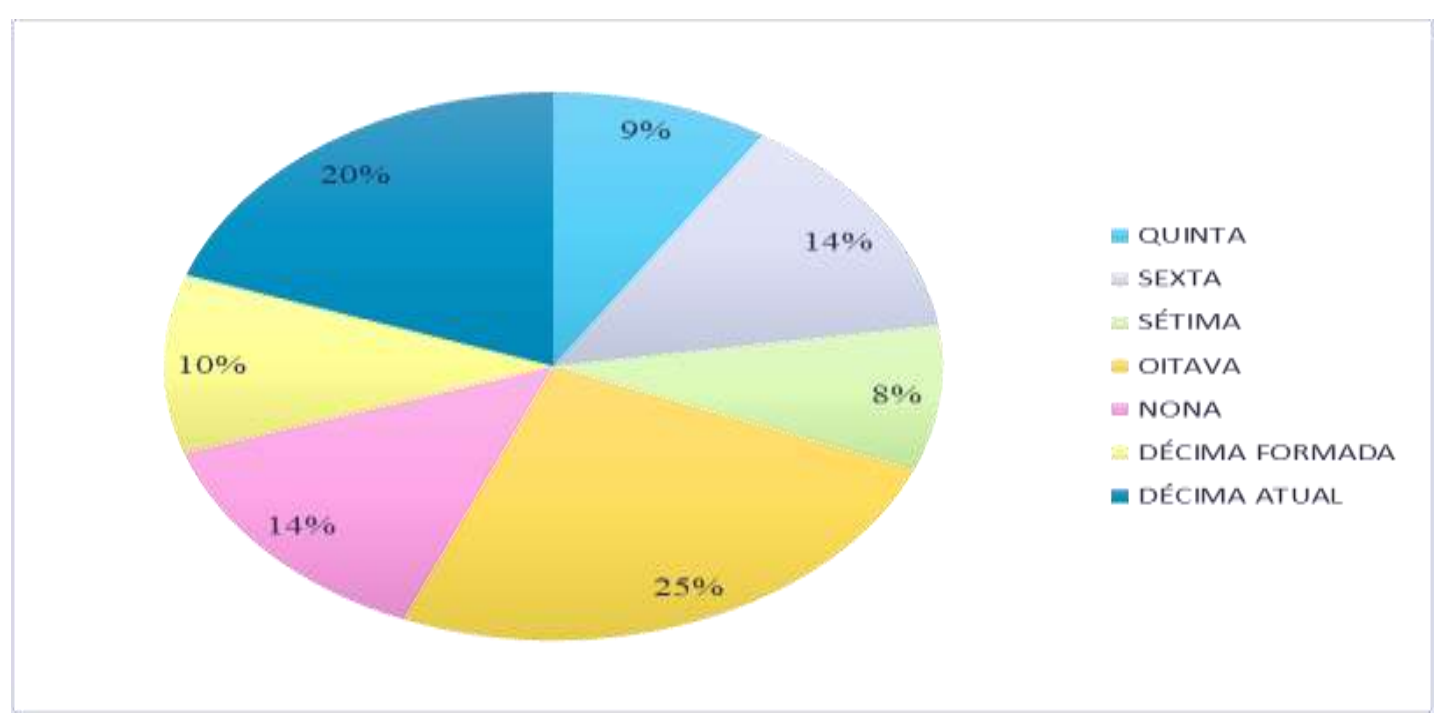

Fonte: Autores.

Quando perguntado se já se depararam com algum caso de câncer oral, 97\% responderam que não. Ao serem questionados sobre quais fatores de risco estão relacionados com o câncer bucal, 37,2\% responderam álcool, tabaco e exposição solar (Figura 3), contudo, no estudo de Santos et al. (2014), o tabagismo (92,5\%) e etilismo (84,2\%) são citados como fatores de risco. Conforme estudos de Neville et al. (2009), o câncer ocorre devido ao crescimento desordenado das células. Em sua maioria, 94,5\% dos acadêmicos responderam corretamente.

Figura 3. Fatores de risco que estão relacionados com câncer bucal.

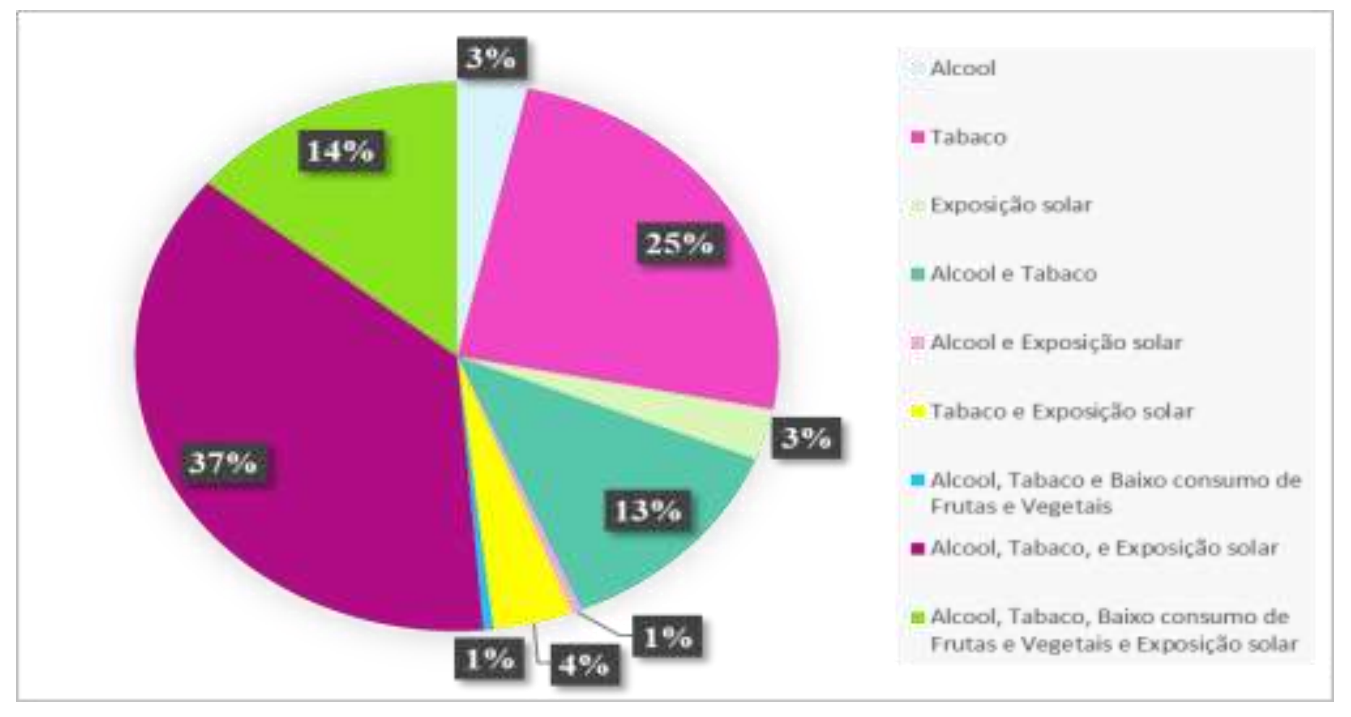

Fonte: Autores.

Podemos considerar satisfatório, visto que dificilmente atinge-se a totalidade de acertos numa questão. Ao perguntar como ocorre o câncer, 94,5\% responderam corretamente que é devido ao crescimento desordenado das células. Sobre o aspecto mais comum, 75,4\% acertaram, respondendo lesão indolor e bordos rígidos. E o tipo mais comum que é o carcinoma espinocelular (CEC), 
44,7\% acertaram, porém houve grande dúvida nesta questão, assim como achados no estudo de Pinheiro, Cardoso, Prado (2010), no qual 83,3\% concordam com essas características da lesão.

Ao serem interrogados sobre uma úlcera na língua que não cicatriza por um período acima de 15 dias, se ela pode representar risco de câncer bucal, 88,4\% responderam que sim, e que é necessário procurar um cirurgião-dentista. Neville et al. (2009), evidenciam que uma lesão que não cicatriza há mais de 15 dias, é recomentado procurar um profissional capacitado, para acompanhamento e análise desta.

No presente estudo, foram citados quais locais são mais acometidos pelo câncer oral, os lábios e a língua em 71,9\%. Ao comparar com o estudo de Andrade, Santos, Oliveira (2015), as regiões citadas por serem as mais acometidas pelo câncer oral, são língua (40,5\%) e assoalho bucal (20,6\%). Soares et al. (2014), apontaram que 53,3\% consideram a língua a região mais afetada. De acordo com as respostas, a faixa etária mais acometida pelo câncer é acima de 40 anos, 81,9\% responderam corretamente à questão, 79,9\% responderam que o câncer de boca promove dor em estágios avançados, como também apontado por Prado, Andrade (2016) em $93,1 \%$ das respostas e de Souza et al. (2017) em 81,4\%. Houve uma diferença estatisticamente significante entre os grupos $(\mathrm{P}=$ 0,007, pelo teste de Qui-quadrado).

Ao questionar sobre a sintomatologia do câncer bucal, 79,9\% dos acadêmicos responderam que não promove dor, mesmo em estágio avançado. Dados que diferem do estudo de Ni Riordan e Mccreary (2009), que apontam em seu estudo que o câncer bucal em estágios avançados apresenta dor, edema e linfadenopatia.

Ao questionar como é possível prevenir o câncer de boca, 98,5\% dos alunos responderam que, não fumando, evitando ingerir bebidas alcoólicas, e utilizando protetor solar, também $98 \%$ disseram que sua prevenção depende da contribuição das pessoas além de conscientizar a população dos fatores de risco, para poder evitá-los. Complementando isso, Lopes et al. (2020) também apontam como fatores de prevenção, a remoção destes fatores de risco.

Quando indagados sobre quais destas lesões são consideradas potencialmente malignas, a eritroplasia é a mais citada neste estudo com 44\% das respostas, em segundo lugar a leucoplasia 12,6\% (Figura 4). Comparados aos estudos de Prado e Andrade (2016), 90,2\% relataram ser a leucoplasia e em segunda opção a eritroplasia com 72,5\%.

Figura 4. Lesões consideradas potencialmente malignas.

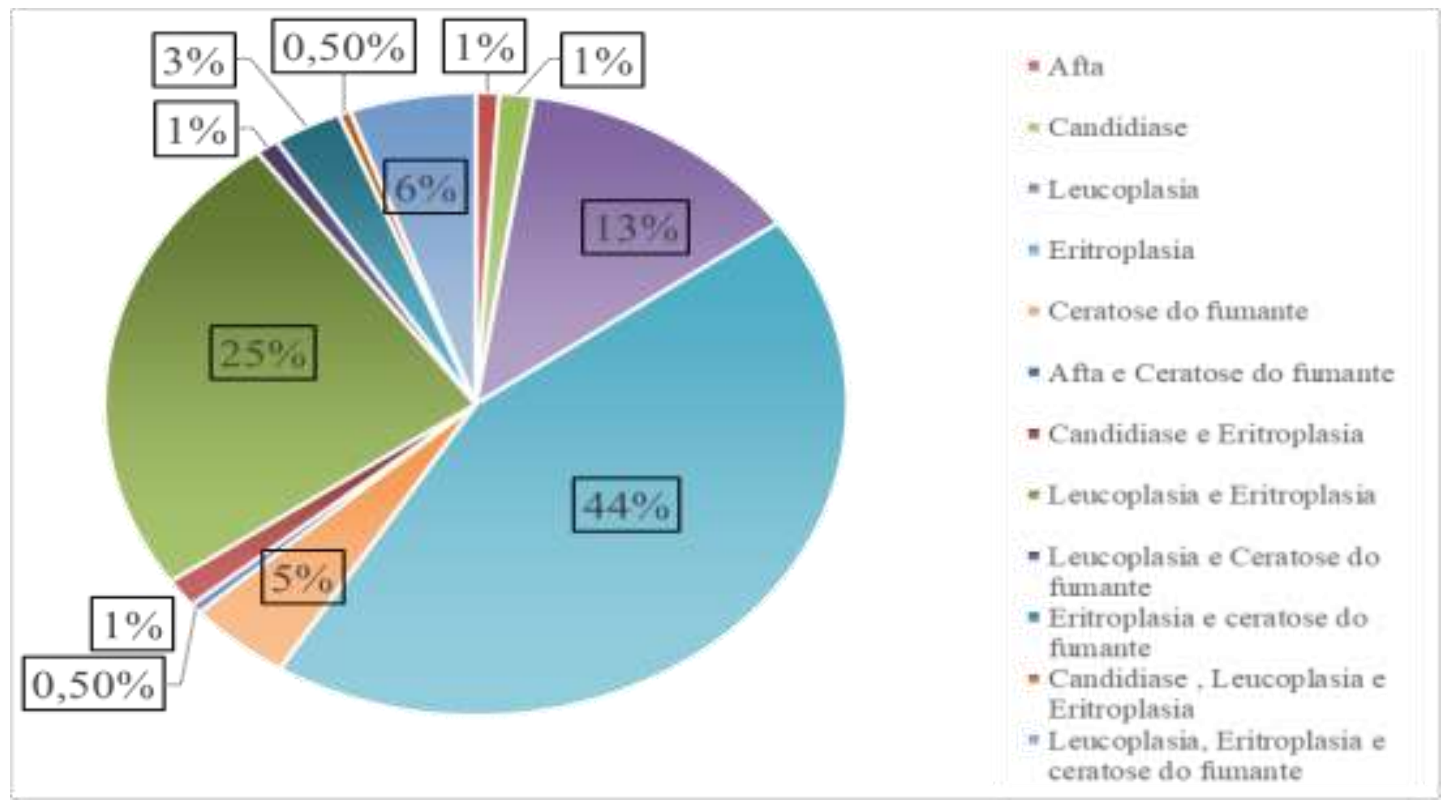

Fonte: Autores. 
Sobre as leucoplasias apresentarem potencial de malignização superior ao das eritroplasias, 70,4\% responderam que sim. Dados estes que discordam do estudo de Kuffer e Lombardi (2002), que apontam a eritroplasia com maior potencial de malignização. Já no estudo de Martins et al. (2008), foram apontadas como as lesões com maior potencial de malignização a queilite actínia e leucoplasia.

Já sobre qual estágio de diagnóstico mais comum de câncer bucal, houve concordância nas respostas 75,8\% dos alunos da clínica não integrada e 91,2\% da clínica integrada relataram que o diagnóstico é obtido em estágio avançado. Dados estes que concordam com o estudo de Martins et al. (2008), no qual os acadêmicos de anos iniciais e os de anos finais, relatam que os pacientes chegam para atendimento em estágio avançado da doença. Houve uma diferença estatisticamente significante entre os grupos $(\mathrm{P}=$ 0,002 , pelo teste $\mathrm{t}$ ).

Quando questionados se a comprovação definitiva de alteração maligna é fornecida pela citologia esfoliativa, 71,4\% dos alunos responderam que sim, errando a questão $(\mathrm{P}=0,002$, pelo teste $\mathrm{t}$ ). A citologia esfoliativa é um exame complementar que ajuda na deteç̧ão precoce do câncer bucal, dados que concordam com o estudo de Freitas et al. (2016), onde cita que a citologia ajuda a identificar lesões em estágios iniciais, e é muito usada para pacientes com grande potencial de risco, por fazerem uso de cigarro e álcool. É importante considerar, no entanto, que a citologia esfoliativa não é rotina em serviços de diagnóstico de câncer bucal. O exame padrão-ouro para diagnóstico será sempre a biópsia, seguida de exame histopatológico da peça biopsiada.

Quanto ao auto-exame, 60,8\% dos acadêmicos responderam que é possível sim uma pessoa realiza-lo. O cirurgião-dentista tem importante papel em ensinar o paciente a fazer o auto-exame em casa, principalmente os pacientes que são expostos aos fatores de risco e que não tem acesso rápido ao atendimento clínico (Prado \& Passarelli, 2009). Quando perguntado sobre qual profissional é responsável pelo tratamento, $48,7 \%$ disseram que o tratamento do câncer oral está sob a responsabilidade do médico ou cirurgiãodentista. Já sobre o estágio de diagnóstico mais comum de câncer bucal, 86,4\% responderam avançado. Esses dados que não concordam com o estudo de Silva et al. (2016) apontam como responsável pelo tratamento o cirurgião-dentista. Já no estudo de Cristina e Cangussu (2010), relatam o médico especialista em cabeça em pescoço como o principal responsável pelo tratamento. Santos, Dib, Souza (2020) abordam a importância do cirurgião-dentista no diagnóstico inicial, e preventivo, mas é necessária uma equipe multidisciplinar para dar sequência ao tratamento.

O câncer está entre a principal causa de morte no mundo, devido a vários novos fatores associados, como estilo de vida (hábitos, sedentarismo), e fatores de riscos. Na estimativa de câncer, no mundo em 2018, estima-se 17 milhões de novos casos de câncer, e 9,5 milhões de novas mortes (excluindo os cânceres de pele não melanoma). Sendo que, o câncer bucal está na quinta posição para homens, e na décima posição para mulheres (INCA, 2019). É importante que os acadêmicos tenham claro o papel do cirurgião-dentista no diagnóstico e na assistência do paciente ao longo do tratamento, mas que o responsável pelo tratamento oncológico será o médico oncologista.

Este estudo possui limitações. Foi utilizado um questionário de auto-preenchimento. isto pode ter o viés da interpretação das perguntas. Também aconteceram perdas de acadêmicos que não quiseram participar, e por perdas de resposta, muito provavelmente em função do auto-preenchimento. Portanto, na presente pesquisa pode-se perceber que os acadêmicos se sentem pouco confiantes para diagnosticar e fazer um bom exame físico no paciente. Isto pode estar relacionado ao fato de os mesmos não terem tido nenhuma ação prática na faculdade, na qual aborde e ensine a fazer o exame para avaliar lesões suspeitas de malignização, tendo em vista que o conhecimento da teoria e da prática clínica, é essencial para um bom diagnóstico e primordiais para a detecção precoce desta displasia.

\section{Conclusão}

Portanto, a partir dos resultados apresentados, conclui-se que o geral conhecimento dos acadêmicos é positivo. A maioria soube a definição de câncer bucal, responderam que uma úlcera que não cicatriza há mais de 15 dias deve ser investigada, que a faixa 
etária mais acometida é acima de 40 anos, que a língua é o local mais afetado, sabem dos fatores de risco, que a lesão mais frequente é o carcinoma espinocelular e que o diagnóstico do câncer oral acontece em estágio avançado, por isso a importância da prevenção, pois quanto mais tarde, mais difícil é a chance de sucesso no tratamento. Grande parte dos estudantes relataram ter pouca confiança, porém as respostas foram assertivas.

É de suma importância o conhecimento do cirurgião-dentista frente ao diagnóstico do câncer bucal, sendo a disciplina de patologia bucal de grande valia como fonte de conhecimento tanto para diagnóstico precoce quanto para a prevenção deste. A trajetória acadêmica contribui diretamente na vida profissional, pois alia o conhecimento teórico com o prático. A soma dos aprendizados adquiridos contribui para que os acadêmicos tenham mais discernimento de lesões potencialmente malignas, chegando assim a um diagnóstico precoce, contribuindo com informações de autoexame e ajudando os pacientes a procurar o atendimento prévio.

\section{Referências}

Andrade, J. O. M., Santos, C. A. S. T., \& Oliveira, M. C. (2015). Fatores associados ao câncer de boca: Um estudo de caso-controle em uma população do Nordeste do Brasil. Rev. Bras. epidemiol, 18(4):894-905.

Angheben, P. F., Salum, F. G, Cherubini, K., \& Figueiredo, M. A. Z. (2013). Perfil de conhecimento sobre câncer bucal dos alunos da faculdade de odontologia da Pontifícia Universidade Católica do Rio Grande do Sul. Rev Odontol Bras Central, 21(60):33-40.

Assis, R. C., Ribeiro, M. S, Ferreira, L. P., Martins, A. G., Barreto, L. R., \& Cerqueira, J. D. M. (2020). Associação entre o câncer de boca e a presença do HPVRevisão integrativa. Revista de Divulgação Científica Sena Aires, 9(2):344-35.

Bittencourt, C. P., Abreu, M. C., Souza, T. F., Hot, A. D., \& Partata, A. K. (2017). Tabagismo e sua relação com o desenvolvimento de câncer. Revista Científica Do ITPAC, 10(1):14-18.

Carrard, V. C., Pires, A. S., Paiva, R. L., Chaves, A. C. M., \& Filho, M. S. (2008). Álcool e câncer bucal: Considerações sobre os mecanismos relacionados. Rev. Bras. Cancerol., 54(1):49-56.

Castillo, K. A., Pereira, T. T. M., Paes, G. B., \& Barros R. M. G. (2012). Levantamento epidemiológico do câncer bucal: casuística de 30 anos. Rev. Fac. Odontol, 53(2):19-23.

Canto, M. T., Horowitz, A. M., Drury, T., \& Goodman, H. S. (2002). Maryland family physicians' knowledge, opinions and practices about oral cancer. Oral Oncol. 38(5): 416-24.

D'agulham, A. C. D., Chaiben, C. L., Lima, A. A. S., Torres-Pereira, C. C., \& Machado, M. A. N. (2014). Fanconi Anemia: main oral manifestations. RGO - Revista Gaúcha de Odontologia, 62(3):281-288.

Farah, C. S., Jessri, M., Currie, S., Alnuaimi, A., Yap, T., \& McCullough, M. Aetiology of oral cavity cancer. In: Kuriakose, M. A., editor. Contemporary oral oncology: biology, epidemiology, etiology, and prevention. Springer, 2017.

Furtado, L. S. F. A., Sales, J. L. A. M., Fontes, M. N., Batista, M. I. H. DE. M., Carvalho, A. A. T., \& Paulino, M. R. (2019). Câncer bucal, desordens potencialmente malignas e prevenção: uma revisão integrativa. REFACS. Revista Família, Ciclos de Vida e Saúde no Contexto Social, 7(4):479.

Freitas, R. M., Rodrigues, A. M. X., Junior, A. F. M., \& Oliveira, G. A. L. (2016). Fatores de risco e principais alterações citopatológicas do câncer bucal: uma revisão de literatura. RBAC. 48(1):13-8.

Goyal, G., \& Bhagawati, B. T. (2016). Knowledge, Attitude and Practice of chewing gutka, areca nut, snuff and tobacco smoking among the young population in the Northern India Population. Asian Pacific Journal of Cancer Prevention, 17(11):4813-4818.

IARC Working Group on the Evaluation of Carcinogenic Risks to Humans. Tobacco smoke and involuntary smoking. IARC Monogr Eval Carcinog Risks Hum. $2004,83: 1-1438$.

Inca (Instituto Nacional de Câncer José Alencar Gomes da Silva) (2006). A situação do câncer no Brasil / Ministério da Saúde, Secretaria de Atenção à Saúde, Instituto Nacional de Câncer, Rio de Janeiro. Disponível em: Biblioteca Virtual em Saúde Prevenção e Controle de Câncer (http://controlecancer.bvs.br/). e no Portal do INCA (http://www.inca.gov.br/). Acessado em: 15/05/2020.

Inca (Instituto Nacional de Câncer José Alencar Gomes da Silva) (2020). Incidência de Câncer no Brasil. Rio de Janeiro. Disponível em: Biblioteca Virtual em Saúde Prevenção e Controle de Câncer (http://controlecancer.bvs.br/). e no Portal do INCA (http://www.inca.gov.br/).

Kuffer, R., \& Lombardi, T. (2002). Premalignant lesions of theoral mucosa. A discussion about the place of oral intraepithelial neoplasia (OIN). Oral Oncol., 38(2):125-30.

Khalili, J. (2008). Oral cancer: Risk factors, prevention and diagnostic. Experimental Oncology, 30(4):259-264.

Lopes, F. F., Oliveira, A. E. F., Cruz, M. C. F. N., \& Miranda, M. R. (2015). Nível de conhecimento e atitudes preventivas entre universitários do curso de odontologia da UFMA em relação ao câncer bucal. Rev. G\&amp, 6:2039-2052 
Lamin, C. D. A., Silva, M. A. M., \& Souza, M. C. A. (2011). Conhecimento dos acadêmicos do curso de odontologia da USS sobre os fatores de risco para o câncer bucal. Revista ProuniverSUS, 2(2): 5-16.

Lopes, R. B., França, M. M. C., Júnior, J. J. V., Sousa, G. A, Sousa, E. A. R., \& Mendes, E. M. (2020). Principais complicações orais da radioterapia de cabeça e pescoço: Revisão de literatura. Revista de Odontologia Contemporânea, 4(1):68-74.

Maia, H. C. DE M., Pinto, N. A. S., Pereira, J. dos. S., Medeiros, A. M. C., Silveira, E. J. D. DA., \& Miguel, M. C. DA. C. (2016). Potentially malignant oral lesions: clinicopathological correlations. Einstein (São Paulo, Brasil), 14(1):35-40.

Mauricio, H. DE A., Matos, F. C. M, \& Guimarães, T. M. R. (2009). Conhecimentos, atitudes e práticas sobre câncer de boca da comunidade atendida pelo PSF de São Sebastião do Umbuzeiro/PB. Rev. bras. cir. Cabeça Pescoço, 38(1):10-14

Martins, M. A. T., Marques, F. G. O. A., Pavesi, V. C. S., Romão, M. M. A., Romão, C. A., \& Martins, M. D. (2008). Avaliação do conhecimento sobre o câncer bucal entre universitários. Rev. bras. cir. Cabeça Pescoço, 37(4): 191-197

Moreira, M. B. R., Buexm, L. A., Oliveira, S. P., Alves, A. T. N. N., Faria, P. A. S., Dias, F. L., \& Lourenço, S. Q. C. (2017) Sarcoma pleomórfico indiferenciado oral: Relato de caso. Revista fluminense de odontologia,1413-2466,2316-1256.

Melo, L. C, Silva, M. C., Bernardo, J. M. P., Marques, E. B., \& Leite, I. C. G. (2010). Perfil epidemiológico de casos incidentes de câncer de boca e faringe. $R G O .58(3): 351-5$

Miloro, M., et al. Princípios de cirurgia bucomaxilofacial de Peterson. (3a ed.), Santos Editora, 1344 p.

Neville, B., Damm, D., Allen, C., \& Bouquot, J. Patologia Oral e Maxilofacial. (3a ed.), analises. Elsevier, 972p p.2009.

Moro, J. DA S., Maroneze, M. C., Ardenghi, T. M., L. M., \& Danesi, C. C. (2018). Oral and oropharyngeal cancer: epidemiology and survival analysis. Einstein (São Paulo, Brasil), 16(2):1-5.

Organização Mundial Da Saúde. Public Health. WHO/OMS, 2020.Instituto Brasileiro de Geografia e Estatística. Síntese dos indicadores sociais: uma análise das condições de vida da população brasileira. IBGE, 2019. https://biblioteca.ibge.gov.br/visualizacao/livros/liv98965.pdf.

Oliveira, J. M. B., Pinto, L. O., Lima, N. G. M., \& Almeida, G. C. M. (2013). Enfermería en cuanto a los factores de riesgo y procedimientos diagnósticos. Revista Brasileira de Cancerologia, 59(2):211-218.

Pinheiro, S. M. S., Cardoso, J. P., \& Prado, F. O. (2010). Conhecimentos e diagnóstico em câncer bucal entre profissionais de odontologia de Jequié, Bahia. Revista Brasileira de Cancerologia, 56(2):195-205.

Prado, B. N., \& Passarelli, D. H. C. (2009). Uma nova visão sobre prevenção do câncer bucal no consultório odontológico. Revista de Odontologia da Universidade Cidade de São Paulo, 21(1):79-85.

Prado, F. O., \& Andrade, D. L. S. (2016). Conhecimento e atitudes de acadêmicos de odontologia sobre câncer bucal. Archives of Health Investigation, 5(2):90-97. Roco, Á., Cerda, B., Cayún, J. P., Lavanderos, A., Rubilar, J. C., Cerro, R., Acevedo, C., Cáceres, D., Varela, N., \& Quiñones, L. A. (2018). Pharmacogenetics, tobacco, alcohol and its effect on the risk development cancer farmacogenética, tabaco, alcohol y su efecto sobre el riesgo de desarrollar cáncer. Revista Chilena de Pediatria, 89(4):432-440.

Sakaguti, S. A. K. (2018). Tipos de tabaco e bebidas alcoólicas e câncer de cabeça e pescoço. Tese de Doutorado, Faculdade de Saúde Pública, Universidade de São Paulo, 10.11606/T.6.2018.tde-04052018-104023.

Santos, E. S., Sá, J. O., \& Lamarck, R. (2019). Manifestações orais da sífilis: revisão sistematizada de literatura. Archives of Health Investigation, 8(8):413-416.

Santos, A. L., Dib, J., \& Souza, L. (2020). A importância do diagnóstico precoce no tratamento do câncer de orofaringe: Estudo de caso. Amazônia Science and Health, 8(2):100-109.

Santos, G. L., Freitas, V. S., Andrade, M. C., \& Oliveira, M. C. (2010). Fumo e álcool como fatores de risco para o câncer bucal. Odontologia Clínico-Científica (Online), 9(2):131-133.

Santos, L.C., Batista, O. M., \& Cangussu, M. C. T. (2010). Characterization of oral cancer diagnostic delay in the state of Alagoas. Braz J Otorhinolaryngol.76(4):41622 .

Silva, S. R., Juliano, Y., Novo, N. F. \& Weinfeld, I. (2016). Comparative study of knowledge about oral cancer among undergraduate dental students. Einstein (Sao Paulo, Brazil), 14(3):338-345.

Silva, H. P DA., Zamberlan, C., Birk, N., \& Ilha, S. (2018). Fatores que influenciam na alteração do estado nutricional de pacientes oncológicos S., 19(2):267-279. Soares, S. E. (2002). Phenolic acids as antioxidants. Revista de Nutricao, 15(1):71-81.

Soares, T. R. C., Carvalho, M. E. A., Pinto, L. S. S., Falcão, C. A., Matos, F. T. C., Santos, T. C. al. (2014). Oral cancer knowledge and awareness among dental students. Brazilian Journal of Oral Sciences, 13(1):28-33.

Souza, G. T., Fonseca, L. G., Araújo, A. M. B., Freitas, D. A., \& Sousa, A. A. D (2017). Conhecimento de estudantes de odontologia sobre os fatores de risco para o câncer bucal TT - Knowledge of dental students regarding the risk factors for oral câncer. Arq. odontol, 53:1-9.

Tamura, D., Digiovanna, J. J., Khan, S. G., \& Kraemer, K. H. (2014). Living with xeroderma pigmentosum: Comprehensive photoprotection for highly photosensitive patients. Photodermatology Photoimmunology and Photomedicine, 30(2-3):146-152.

Velleuer, E., Dietrich, R., PomjanskI, N., Araujo, I. K. S. A., Araujo, B. E. S., Sroka, I., Biesterfeld, S., Böcking, A., \& Böcking, A. M. (2020). Diagnostic accuracy of brush biopsy-based cytology for the early detection of oral cancer and precursors in Fanconi anemia. Cancer Cytopathology, 128(6):403-413.

Yokoi, A., MAruyama, T., Yamanaka, R., Ekuni, D., Tomofuji, T., Kashiwazaki, H., Yamazaki, Y., \& Morita, M. (2015). Relationship between acetaldehyde concentration in mouth air and tongue coating volume. Journal of Applied Oral Science, 23(1):64-70. 